\title{
Subperiosteal hematoma from peribulbar block during cataract surgery leading to optic nerve compression in a patient with parahemophilia
}

This article was published in the following Dove Press journal:

International Medical Case Reports Journal

3 December 2015

Number of times this article has been viewed

\author{
Sudarshan Khokhar' \\ Bhagabat Nayak' \\ Bharat Patil' \\ Milind Devidas Changole' \\ Gautam Sinha' \\ Reetika Sharma' \\ Lipika Nayak² \\ 'Dr RP Centre for Ophthalmic \\ Sciences, All India Institute of \\ Medical Sciences, New Delhi, India; \\ ${ }^{2}$ Department of Pediatrics, Loknayak \\ Hospital, Maulana Azad Medical \\ College, Delhi, India
}

\begin{abstract}
A 17-year-old male presented with gradual painless diminution of vision since childhood. Slit lamp examination revealed both eyes having congenital cataract. Right eye lens aspiration was performed but was uneventful, and he prepared for left eye surgery after 7 days. Immediately after giving a peribulbar block, a complete akinesia, tight eyelids, and stony hard eyeball was noted. An abaxial proptosis of $7 \mathrm{~mm}$ was noted. Lateral canthotomy and inferior cantholysis were done and proptosis reduced to $5 \mathrm{~mm}$. Bleeding time-clotting time was normal. Proptosis worsened to $8 \mathrm{~mm}$ the next day. Contrast-enhanced computed tomography scan showed inferolateral subperiosteal hematoma, but drainage could not be performed due to prolonged prothrombin time and activated prothrombin time. Fresh frozen plasma was transfused. Tarsorrhaphy was performed for exposure keratopathy after his coagulation profile became normal. Hematology evaluation after 2 weeks detected factor V deficiency, and was diagnosed as Owren's disease or parahemophilia.
\end{abstract}

Keywords: peribulbar block, hematoma, subperiosteal, parahemophilia, optic nerve compression

\section{Introduction}

Satisfactory anesthesia is prerequsite for the performance of safe intraocular surgery. Ophthalmic anestheia has evolved over years from "no-anesthesia" couching to "no-anesthesia" phacoemulsification. Still, regional anesthesia is widely used in ophthalmology. Unless contraindicated, cataract surgery is usually performed under regional/topical anesthesia. Regional anesthesia is the blockage of a nerve subserving a given part of the body by infiltrating the area around the nerve with local anesthetic. In the eye, the periocular area is infiltrated to block all the nerves around the globe. The goal is to provide safe, painless, efficient, and effective local anesthesia. ${ }^{1}$ Although, regional anesthesia is safe, serious complications do occur, even in expert hands.

We present a case of subperiosteal hematoma after peribulbar block in young myopic male, who was later found to have coagulopathy.

\section{Case report}

A 17-year-old male from north-east part of India was presented to us with gradual painless diminution of vision and abnormal eye movements noticed by parents since 2 years of age. He was using power eight diopter myopic glasses since last 5 years for both the eyes. On examination, he had best corrected visual acuity (BCVA) of 20/200 in both the eyes with latent/manifest nystagmus. Slit lamp examination revealed congenital cataract (involving fetal and embryonic nucleus) in both the eyes. Ultrasound
Correspondence: Bhagabat Nayak Ophthalmic Sciences, All India Institute of Medical Sciences, Ansari Nagar, New Delhi I I0049, India

Tel +9l II 26593133

Fax +9| || 2658 8|3|

Email bhagabat80@gmail.com 
biometry showed axial length of $26 \mathrm{~mm}$ in both eyes. Diagnosis of high myopia with congenital cataract with manifest/latent nystagmus was made in both the eyes. Preoperative work-up for intraocular power calculation was done. Routine blood investigations like hemoglobin, total leukocyte count, and platelet count were within normal range. After informed consent was taken from the parents, he was posted for lens aspiration under peribulbar block in both the eyes. Right eye lens aspiration was uneventful. Day 1 post-op showed a BCVA of 20/60 and subconjunctival hemorrhage was noted. He was posted for left eye surgery by the same surgeon after 7 days. A peribulbar block using $26 \mathrm{G} 12.5 \mathrm{~mm}$ needle was given in the left eye after the lower lid retracted manually, and the needle was placed half way between the lateral canthus and the lateral limbus. The needle was advanced in the sagittal plane, parallel to the orbital floor passing under the globe. When the needle tip was judged to be past the equator of the globe, the direction was changed to a point slightly medial $\left(20^{\circ}\right)$ and cephalad $\left(10^{\circ}\right.$ upward) to avoid the bony orbital margin. The needle was advanced without any resistance till the hub of the needle was at the depth similar to that of the iris plane. Following negative aspiration, $5 \mathrm{~mL}$ of local anesthetic agent (a mixture consisting of equal volumes of $2 \%$ lignocaine and $0.75 \%$ bupivacaine with hyaluronidase $7.5 \mathrm{IU} / \mathrm{mL}$ ) was injected. Immediately after giving a peribulbar block, a complete akinesia, subconjunctival hemorrhage, tight eyelids, and stony hard eyeball was noted. Surgery was cancelled, a provisional diagnosis of left eye retrobulbar hemorrhage was made, and he was immediately started on intravenous (IV) mannitol $250 \mathrm{~mL}$ (7 mL/kg). Patient was reviewed after an hour. An abaxial proptosis of approximately $7 \mathrm{~mm}$, inferior dystopia with ecchymosis, and subconjunctival hemorrhage was noted (Figure 1A and B); intraocular pressure (IOP) was $30 \mathrm{mmHg}$. Lateral canthotomy and inferior cantholysis were performed by our oculoplasty colleague on emergency basis under local infiltration of a mixture of lignocaine $2 \%$ and adrenaline (1 in 20,000) and he found it difficult to control the bleed- ing. He managed to reduce proptosis to $5 \mathrm{~mm}$ and IOP was $22 \mathrm{mmHg}$. Indirect ophthalmoscopy showed no evidence of intraocular or subretinal bleeding, and central retinal artery pulsations were inducible after giving pressure over eyeball with cotton tip applicator. A pulse dexamethasone therapy for 3 consecutive days, $100 \mathrm{mg}$ in $150 \mathrm{~mL}$ of $5 \%$ dextrose over 2-3 hours daily, was started. Topical eye drop moxifloxacin $0.5 \%$ qid (four times a day) and eye drop prednisolone acetate $1 \%$ qid were started. Oral acetazolamide $250 \mathrm{mg}$ qid and topical eye drop timolol $0.5 \%$ bid was given to control IOP. Frequent lubrication was given to prevent exposure keratopathy. Due to uncontrolled bleeding, coagulation abnormality was suspected and bleeding time-clotting time was determined immediately, which came to be normal. Proptosis worsened to $8 \mathrm{~mm}$ next day. A contrast-enhanced computed tomography (CECT) scan showed inferolateral subperiosteal hematoma in the left eye (Figure 2). He was posted for drainage of subperiosteal hematoma, but due to strong clinical suspicion of coagulation disorder, prothrombin time (PT) and activated prothrombin time (aPTT) were determined, which were observed to be prolonged, that is, PT was 22 seconds and aPTT was 50 seconds. So drainage of hematoma was cancelled. Fresh frozen plasma was transfused for stabilization of coagulation factor deficiency. After 5 days, coagulation profile came to be within normal range and tarsorrhaphy was performed for exposure keratopathy. Repeat hematology evaluation after 2 weeks detected factor $\mathrm{V}$ deficiency. He was diagnosed to have Owren's disease or parahemophilia.

Our first important differential diagnosis was retrobulbar hemorrhage which was ruled out after CECT scan, and the second differential diagnosis was any coagulopathy which was supported by PT and aPTT and confirmed by coagulation factor assay.

At discharge, he had BCVA of 20/80 in right eye and no perception of light (No PL) in left eye due to compressive optic neuropathy. On 7 days follow-up, there was a healing corneal ulcer of $3 \times 2 \mathrm{~mm}$ size, and after 2 weeks of follow-up the ulcer healed completely with No PL in the left eye. Three

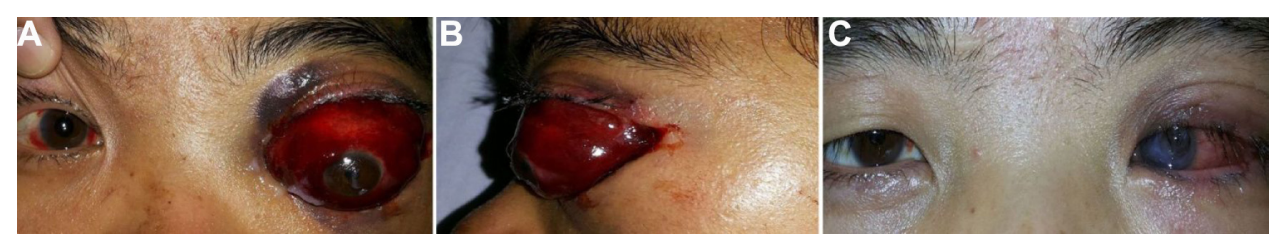

Figure I Clinical photograph of patient after peribulbar block.

Notes: (A) Clinical photograph of patient showing right eye mild subconjuctival hemorrhage and left eye abaxial proptosis with subconjuctival hemorrhage and periorbital ecchymosis. (B) Lateral view of patient showing proptosis with subconjuctival hemorrhage. (C)Three weeks post-operatively, left eye of the patient became pre-phthisical. 


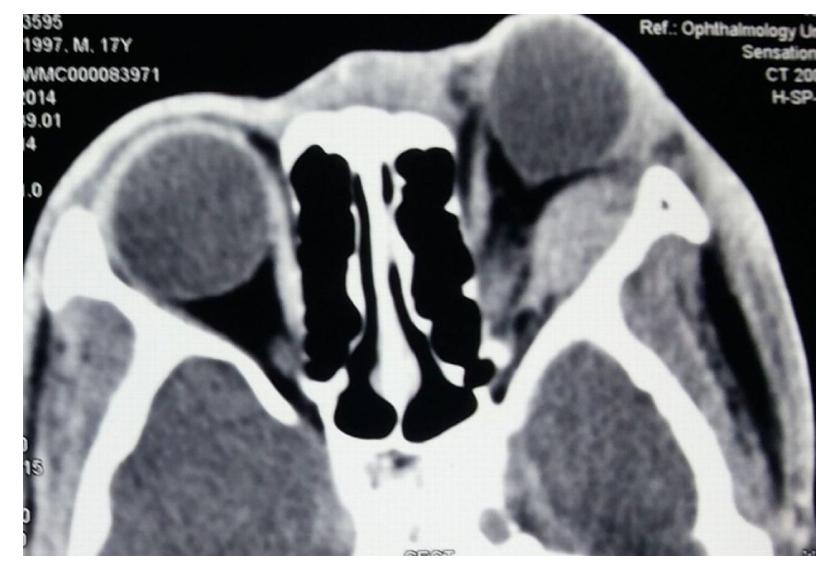

Figure 2 Computed tomography of the orbit with contrast showing left eye proptosis with inferolateral subperiosteal hematoma.

weeks postoperatively, left eye was undergoing phthisis (Figure 1C).

\section{Discussion}

Why we had this complication? Is it due to coagulopathy, or due to highly vascular periosteum in young people, which is loosely adhered to bone, or due to the difficult situation for block? It could be due to combination of all these things. This patient had no history of previous bleeding disorder or any family history. So detected factor V deficiency may be due to an acquired cause like any liver disease or spontaneous autoimmune reactions after surgery. His liver function test was within normal range. So there may be possibility of spontaneous autoimmune reactions after first surgery in the right eye leading to factor $\mathrm{V}$ deficiency temporarily in our case. It has been proved beyond doubt that regional anesthesia does not increase the risk of serious bleeds, and it is not advisable to stop anticoagulants before cataract surgery. ${ }^{2}$ Figure 2 shows large globe filling the orbit. There is hardly any space between the globe and orbital walls. We used $26 \mathrm{G}$ hypodermic needle to give the block. The length of the needle we used was half inch, which has less chance of damaging periocular vascular structures. Moreover, in our case emergency surgical intervention could have been done by transfusing fresh frozen plasma early. This might have prevented the patient from becoming blind.

Mootha et $\mathrm{al}^{3}$ and Nauman et $\mathrm{al}^{4}$ had similar encounters. Both the patients were elderly women without any coagulopathy. They used retrobulbar and peribulbar blocks, respectively. In the first case the patient lost her vision and in the second case the patient was promptly managed, and visual gain was complete.

Average adult orbital volume in South-East Asian population is $23.94 \pm 3.47 \mathrm{~mL}$ and that of Caucasians is $28.41 \pm 2.09 \mathrm{~mL} .{ }^{5}$ The patient in this study was from SouthEast Asian origin with small orbital volume but with large myopic eye ball; this could be another reason for aggravated compartment syndrome and rapidly progressive proptosis, leading to vision loss despite timely intervention.

Nowadays, the technique of retrobulbar block has become obsolete, as it involves more complications in comparison to peribulbar block, because of its long course of needle insertion, leading to complication from intraorbital tissue injury to sight-threatening complications like retrobulbar hemorrhage and optic nerve damage. ${ }^{6}$ Although peribulbar block is not free of any complication, it is still the most preferred practice of block today. Recently, the sub-Tenon's block and the topical anesthesia have gained popularity. Even sub-Tenon's block has its own complication like chemosis and subconjuctival hemorrhage, and hence should be used in cooperative patients with shorter duration of surgery. As our patient was a young patient we preferred peribulbar block with a properly described technique, ${ }^{7}$ and the right eye was without any major complication except mild subconjuctival hemorrhage. So we went ahead with the peribulbar block by same person who has given the right eye block.

The dreaded complication of retrobulbar hemorrhage can be diagnosed by hard eyeball, tight eyelids with ecchymosis, and proptosis. Disappearance of red reflex and loss of direct pupillary response are also the warning signs of retrobulbar hemorrhage. Patient may complain of sudden vision loss or vision blackout due to central retinal artery occlusion. Management depends on severity of the bleed and assessment of ocular circulatory compromise. In all cases, it is advisable to give external ocular pressure. Additional measures include immediate cancellation of surgery and reduction of both IOP and intraorbital pressure by paracentesis, intravenous mannitol, and performing lateral canthotomy and cantholysis. Steroids should be given to reduce inflammation.

\section{Disclosure}

The authors report no conflicts of interest in this work.

\section{References}

1. Hamilton RC, Gimble HV, Strunin L. Regional anaesthesia for 12,000 cataract extractions and lens implant procedures. Can J Anaesth. 1988;35:615-625

2. Emile C, Olivier G, Annie C, et al. Peribulbar anesthesia in 750 patients treated with oral anticoagulants. Int J Ophthalmol. 2014;7:110-113.

3. Mootha VV, Cowden TP, Sires BS, et al. Subperiosteal orbital hemorrhage from retrobulbar injection resulting in blindness. Arch Ophthalmol. 1997;115:123-124.

4. Nauman A, Abdul Z, Sahar ME. Periocular hematoma secondary to subperiosteal injury by a short needle. Saudi J Anaesth. 2012;6: $412-414$. 
5. Deveci M, Ozturk S, Sengezer M, et al. Measurement of orbital volume by a 3-dimensional software program: an experimental study. J Oral Maxillofac Surg. 2000;58:645-648.

6. Palte HD. Opthalmic regional blocks: managements, challenges and solutions. Local Reg Anesth. 2015;8:57-70.
7. Fahmi A, Bowmar R. Administering an eye anesthetics: principles, techniques and complications. Community Eye Health. 2008;21:14-17.

\section{Publish your work in this journal}

The International Medical Case Reports Journal is an international, peer-reviewed open-access journal publishing original case reports from all medical specialties. Previously unpublished medical posters are also accepted relating to any area of clinical or preclinical science. Submissions should not normally exceed 2,000 words or
4 published pages including figures, diagrams and references. The manuscript management system is completely online and includes a very quick and fair peer-review system, which is all easy to use. Visit $\mathrm{http}: / / \mathrm{www}$.dovepress.com/testimonials.php to read real quotes from published authors.

Submit your manuscript here: http://www.dovepress.com/international-medical-case-reports-journal-journal 